\title{
PEMBERDAYAAN KADER POSYANDU DALAM UPAYA PEMANTAUAN PERKEMBANGAN BALITA MELALUI KPSP
}

DOI: https://doi.org/10.33024/jkpm.v4i4.3993

$$
\text { Erna Julianti }{ }^{1^{*}}, \text { Elni }^{1}
$$

\section{Akademi Keperawatan Pangkalpinang}

Disubmit: 07 Maret 2021 Diterima: 09 April 2021 Diterbitkan: 03 Agustus 2021

Email Korespondensi: erna.julianti08@gmail.com

\begin{abstract}
ABSTRAK
Golden age merupakan masa yang sangat penting untuk memperhatikan tumbuh kembang anak secara cermat agar sedini mungkin dapat terdeteksi apabila terjadi gangguan perkembangan. Peran kader posyandu mempunyai peran penting dalam memantau perkembangan anak. Tujuan kegiatan ini yaitu untuk meningkatkan pengetahuan kader posyandu dalam pemantauan perkembangan balita melalui KPSP untuk mencegah gangguan perkembangan pada balita. Metode kegiatan yang digunakan dimasa pandemi ini berupa pemberian pendidikan kesehatan dengan mentode ceramah, tanya jawab, diskusi dan demostrasi kepada kader posyandu dalam pemantauan perkembangan melalui KPSP. Kegiatan pengabdian kepada masyarakat ini dilaksanakan di Puskesmas Air Itama Pangkalpinang. Waktu pelaksanaan bulan Februari 2021. Sasaran adalah Kader Posyandu berjumlah 31 orang. Hasil yang diperoleh adalah terdapat perbedaan yang signifikan antara pengetahuan kader sebelum dan setelah diberikan edukasi tentang pemantau perkembangan balita melalui KPSP dengan $p$ value 0,001 . Adanya peningkatan nilai rata-rata pengetahuan kader posyandu tentang pemantauan perkembangan balita melalui KPSP sebesar 40,32. Diharapkan kader posyandu dapat mengaplikasikan dalam memantau perkembangan balita melalui KPSP sehingga perkembangan balita optimal.
\end{abstract}

Kata kunci: balita, KPSP, kader posyandu, perkembangan

\section{ABSTRACT}

The golden age is a very important period to pay attention to the development of children carefully so that it can be detected as early as possible in the event of developmental disorders. The role of posyandu cadres has an important role in monitoring children's development. The purpose of this activity is to increase the knowledge of posyandu cadres in monitoring the development of toddlers through KPSP to prevent developmental disorders in children under five. The activity method used during this pandemic was in the form of providing health education is by using lectures, question and answer methods, discussions and demonstrations to posyandu cadres in monitoring progress through KPSP. This community service activity was carried out at the Air Itama Pangkalpinang Community Health Center. Implementation time is February 2021. The target is Posyandu cadres. The results obtained were that there was a significant 
difference between the knowledge of the cadres before and after being given education about monitoring the development of toddlers through KPSP with a $p$ value of 0.001 . There was an increase in the average score of posyandu cadres' knowledge about toddler development monitoring through KPSP of 40.32. It is hoped that posyandu cadres can apply it in monitoring the development of toddlers through KPSP so that the development of toddlers is optimal.

Keywords: toddlers, KPSP, posyandu cadres, development

\section{PENDAHULUAN}

Perjuangan dan cita-cita suatu bangsa akan terwujud apabila diteruskan oleh sumber daya manusia yang berkualitas. Anak merupakan sumber daya manusia yang dapat meneruskan perjuangan tersebut, apabila pertumbuhan dan perkembangan baik secara fisik maupun mental dapat optimal (Depkes, 2006). Golden age merupakan masa yang sangat penting untuk memperhatikan tumbuh kembang anak secara cermat agar sedini mungkin dapat terdeteksi apabila terjadi gangguan perkembangan (Azrimaidaliza et al., 2019). Hasil penelitian Jeong JiEun,et.al. (2014) menyatakan bahwa pada saat tes awal, 62 dari 70 anak memiliki indeks perkembangan mental di bawah 70 dilihat dengan Bayley Scales of Infant Development Uji II. Dari 62 anak dalam penilaian tindak lanjut, 30 anak $(48,4 \%)$ masih dalam kisaran kognitif yang sama, 12 anak memiliki fungsi intelektual, 6 ditingkatkan untuk rata-rata fungsi intelektual, dan 5 memiliki gangguan bahasa tertentu, 9 memiliki gangguan spektrum autisme (Eun, Lee, \& Kim, 2014).

Di Indonesia sekitar $16 \%$ anak usia bawah lima tahun (balita) mengalami gangguan perkembangan saraf dan otak, serta gangguan perkembangan motorik. Selain itu, balita yang mengalami gangguan pendengaran, sehingga mengalami keterlambatan dalam kemampuan bicara, yang berdampak pada kurang optimalnya kecerdasan anak (Depkes RI, 2010). Mayoritas anak dengan penyimpangan tumbuh kembang, tidak terdeteksi saat usia prasekolah karena tidak menunjukkan gejala yang jelas apabila tidak dilakukan pemeriksaan dengan instrument standar. Sehingga skrinning perkembangan anak penting untuk dilaksanakan secara rutin (Artha, Sutomo, \& Gamayanti, 2014). Ranah perkembangan anak terdiri atas aspek motorik kasar, motorik halus, bahasa/ bicara, dan personal sosial/ kemandirian. Kasus keterlambatan tumbuh kembang anak secara umum terjadi sekitar 5-10\%. Oleh karena itu perlu adanya deteksi dini terhadap pemantaua perkembangan pada anak balita. Deteksi dini perkembangan anak balita dapat dilakukan dengan menggunakan KPSP (kuesioner pra skring perkembangan) dan Denver II (Hati, \& Lestari, 2016).

Upaya pemenatau pertumbuhan dan perkembangan balita selalu dilakukan. Salah satu kebijakan pemerintah untuk mewujudkan upaya tersebut dengan kegiatan posyandu yang merupakan tempat bagi balita untuk mendapat pelayanan. Pencapaian tujuan kegiatan posyandu yang mulia tersebut, memerlukan peran kader posyandu (Naziyah, Choirunnisa, \& Khoirunnisa, 2020). Kader kesehatan mempunyai potensi yang sangat besar karena kader sangat dekat (dari sisi geografis dan sosial) dengan masyarakat di wilayahnya. Tugas kader menjadi sangat penting dan kompleks dikarenakan 
permasalahan tumbuh kembang pada anak tidak hanya fokus pada fisik saja, namun juga meliputi sosial dan mental anak (Sianturi, Tambunan \& Ningsih 2013). Ellyda, dkk (2018) menyebutkan bahwa minimnya pelatihan dan pembinaan untuk meningkatkan ketrampilan yang memadai bagi kader menyebabkan kurangnya pemahaman kader terhadap tugas dan perannya, lemahnya informasi serta koordinasi antara petugas dan kader dalam pelaksanaan kegiatan posyandu, harus menjadi perhatian yang perlu diperbaiki. Oleh karena itu untuk mengoptimalkan pemantauan perkembangan anak perlu diadakan pelatihan Pemberdayaan kader Posyandu dalam deteksi tumbuh kembang balita melalui KPSP di Puskesmas Air itam.

\section{MASALAH}

Pemantauan perkembangan balita melalui pemeriksaan kuesioner pra skring perkembangan (KPSP) dan pemberian pendidikan kesehatan pada kader posynadu tentang perkembangan anak sangat penting dilakukan sebagai upaya pencegahan terjadinya gangguan perkembangan anak. Kegiatan ini dilakukan di Wilayah Puskesmas Air Itam dikarenakan minimnya pelatihan dan pembinaan kader posyandu menyebabkan kurangnya pemahaman kader terhadap tugas dan perannya harus menjadi perhatian yang perlu diperbaiki. Selain itu, Pemberdayaan kader posyandu penting untuk meningkatkan pengetahuan kader dan keterampilan kader posyandu dalam deteksi atau pemantauan perkembangan balita.

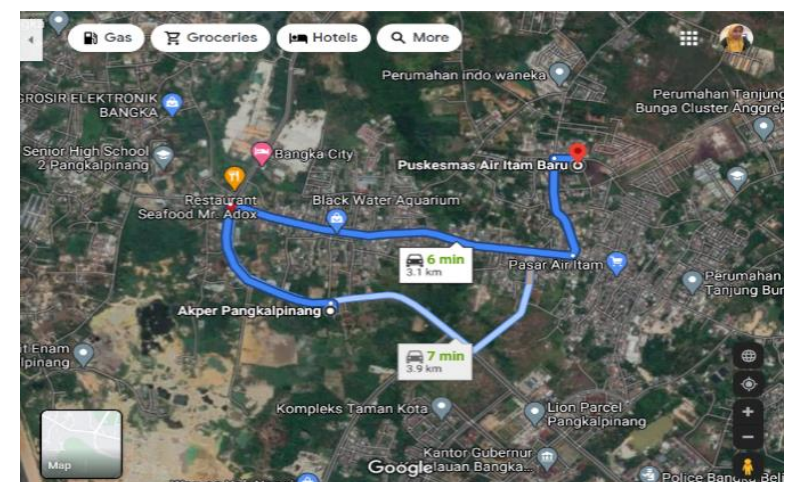

Gambar 2.1. Peta Lokasi Puskesmas Air Itam Pangkalpinang

\section{METODE}

Subjek dalam pengabdian ini sasarannya adalah kader Posyandu di Puskemas Air itam sebanyak 30 kader. Pelaksanaan kegiatan pengabdian kepada masyarakat saat pandemi Covid-19 berbeda dengan pelaksanaan kegiatan saat tidak pandemi Covid-19, karena kegiatan ini memperhatikan rambu-rambu protokol kesehatan dan aturan-aturan yang berlaku dengan mencucui tangan, menjaga jarak dan menggunakan masker. Kegaitan ini dilakasankan di ruang Aula Puskeams Air Itam pada bulan Februari 2021. Pelaksana dan Kader Posyandu sebelum masuk ke ruangan mencuci tangan, dilakukan pengukuran suhu tubuh, tetap menggunakan masker samapi kegaitan selesai dan mengatur jarak tenpat duduk. Tahap persiapan melakukan koordinasi dengan Kepala Puskesmas Air Itam permohonan izin kegiatan, dan Ketua Program Promkes terkait identifikasi mengenai 
pengetahuan kader tentang pemantau perkembangan balita melalui KPSP. Setelah itu, Ketua Program Promkes membuat surat undangan kepada Kader posyandu untuk mengadiri kegiatan pengabdian masyarakat yang dilaksankan oleh dosen akper Pangkalpinang.

Tahap implementasi dengan melakukan kerja sama dengan ketua program Promkes Puskesmas Air itam untuk menjelaskan maksud, tujuan dan manfaat kegiatan ini. Ketua pelaksana membagikan dan menjelaskan pengisian kuesioner pretest kepada kader posyandu. Tujuan pretest ini yaitu untuk mengetahui pengetahuan awal kader tentang pemantauan perkembangan balita. Kegiatan selanjutnya yaitu pemberian pendidikan kesehatan. Metode yang dilakukan dalam Pendidikan kesehatan kepada kader posyandu ini yaitu ceramah, tanya jawab, pemutaran video pemantauan perkembangan serta melakukan demontrasi cara pengisian formulir KPSP sesuai umur anak dan cara menilai perkembangan balita melalui KPSP berdasarkan umur anak. Tahap Evaluasi kegaitan ini yaitu kader posyandu dibagikan kembali kuesioner postest untuk mengetahui pengetahuan kader mengenai pemantauan perkembangan balita melalui KPSP.

\section{HASIL DAN PEMBAHASAN}

Gambaran pengetahuan kader posyandu tentang pemantauan perkembangan balita melalui KPSP sebelum dan setelah diberikan edukasi Kesehatan

Tabel 4.1 Distribusi Pengetahuan Kader Posyandu $(n=31)$

\begin{tabular}{lllll}
\hline $\begin{array}{l}\text { Variabel } \\
\text { Pengetahuan }\end{array}$ & $\begin{array}{l}\text { Mean } \\
\text { (rata-rata) }\end{array}$ & $\begin{array}{l}\text { Standar } \\
\text { Deviasi } \\
\text { (SD) }\end{array}$ & Cl 95\% & P Value \\
\hline Pretest & 45,81 & 13,85 & $40,73-50,89$ & 0,001 \\
\hline Postest & 86,13 & 11,16 & $82,04-90,22$ & \\
\hline
\end{tabular}

Berdasarkan tabel 4.1 didapatakan bahwa nilai rata-rata pengetahuan kader posyandu sebelum diberikan edukasi tentang pemantauan perkembangan balita melalui KPSP sebesar 45,81 dengan standar deviasi sebesar 13,85 sedangkan nilai rata-rata pengetahuan kader posyandu setelah diberikan edukasi tentang pemantau perkembangan balita melalui KPSP sebesar 86,13 dengan standar deviasi sebesar 11,16. Dapat disimpulkan bahawa terdapat perbedaan yang signifikan antara pengetahuan kader sebelum dan setelah biberikan edukasi tentang pemantau perkembangan balita melalui KPSP dengan $p$ value 0,001. Dan terjadi kenaikan nilai rata-rata pengetahuan sebesar 40,32.

Hasil kegiatan pengabdian masyarakat menunjukan bahawa terjadi peningkatan pengetahuan kader posyandu sebelum dan setelah diberikan edukasi kesehatan tentang pemantauan perkembangan balita melalui KPPS. Hal ini sejalan dengan penelitian Putri dan Dewihestie (2020) yang juga menyatakan bahawa ada peningkatan pengetahuan dan ketrampilan kader posyandu balita dalam pemeriksaan deteksi dini tumbuh kembang balita melalui KPSP sehingga kader dapat melakukan deteksi dini tumbuh kembang balita pada saat kegiatan posyandu berlangsung. Hal ini juga 
sejalan dengan penelitian Yuliati dan Harjana (2018) yang menyatakan bahwa ada Peningkatan pengetahuan kader posyandu balita dalam melakukan deteksi dini kelainan tumbuh kembang anak. Peran kader Posyandu sangat penting dalam memantau tumbuh kembang anak balita. Pengetahuan tentang perkembangan anak balita menjadi bekal dalam melaksanakan kegiatan Posyandu. Kader Posyandu dapat mengamati perkembangan anak setiap bulan sehingga dapat memberikan stimulasi yang tepat bagi anak yang datang ke Posyandu. Salah satu starategi untuk perubahan perilaku adalah pemberian informasi guna meningkatkan pengetahuan sehingga timbul kesadaran yang pada akhirnya orang akan berperilaku sesuai dengan pengetahuannya tersebut. Pengetahuan terjadi setelah seseorang melakukan penginderaan terhadap suatu objek atau stimulus (Notoatmodjo, 2012).

Edukasi kesehatan berupa demostrasi dan audiovisual bertujuan mencapai domain pembelajaran yaitu domain kognitif. Domain kognitif merupakan proses berfikir yang dimulai dari kemampuan mengetahui, memahami, aplikasi, melakukan analisis, sintesisi, serta evaluasi tentang pemantau perkembanga balita (Kozier, Erb, Berman, Synder, 2011). Media pembelajaran yang menarik seperti audio vidsual dan demostrasi juga dapat meningkatkan proses atensi dan retensi pembelajaran kader. Media pembelajaran yang digunakan didasarkan pada prinsip bahwa pengetahuan yang ada pada setiap manusia itu diterima atau ditangkap oleh panca indra, semakin banyak indra yang digunakan untuk menerima sesuatu, maka akan semakin jelas pengertian yang diperoleh. Sesuatu yang menimbulkan perhatian, akan memberikan pengertian baru bagi kader dan meningkatakan pemahaman kader tentang pemantau perkembangan balita sehingga dapat diaplikasi oleh kader di posyandu (Notoatmojo, 2010).
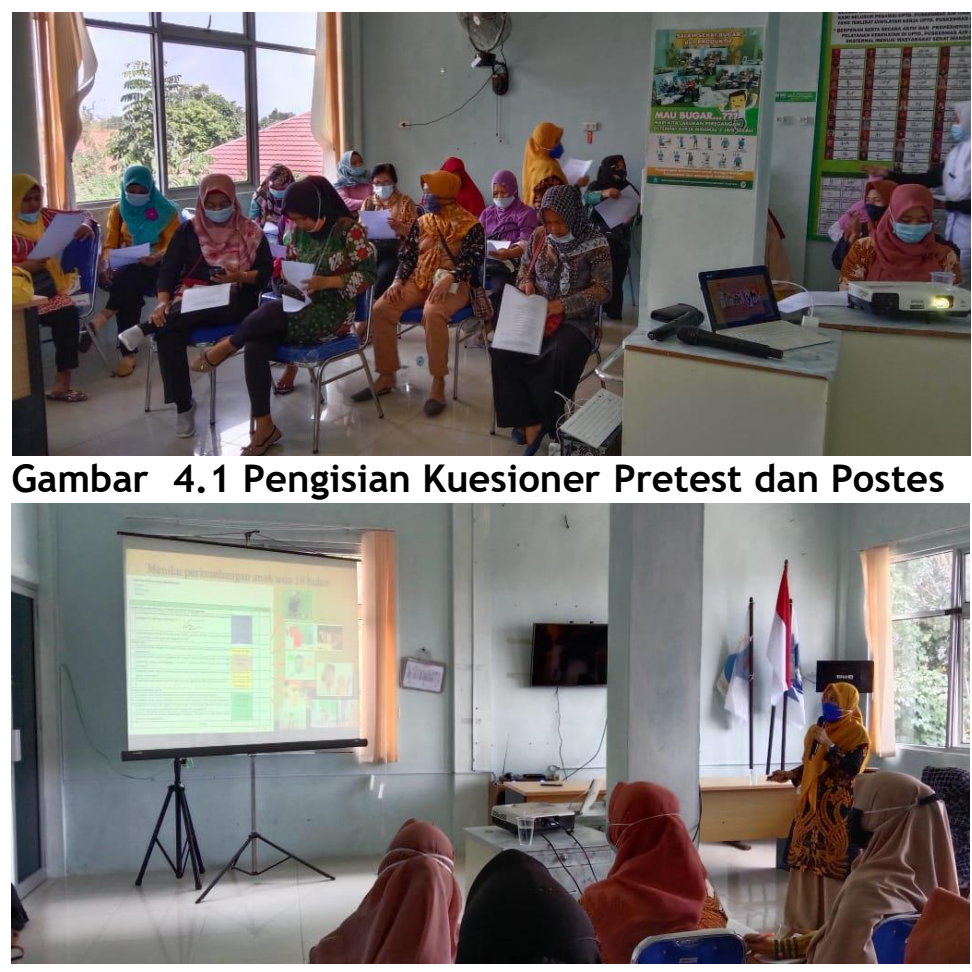

Gambar 4.2 Pemberian Edukasi Kesehatan 


\section{KESIMPULAN}

Simpulan dalam kegiatan pengabdian kepada masyarakat ini adalah terdapat perbedaan yang signifikan antara pengetahuan kader sebelum dan setelah biberikan edukasi tentang pemantau perkembangan balita melalui KPSP dengan $p$ value 0,001 . Dan juga peningkatan nilai rata-rata pengetahuan kader posyandu tentang pemantau perkembanga balita melalui KPSP sebesar 40,32.

\section{DAFTAR PUSTAKA}

Artha, Sutomo \& Gamayanti. (2014). Kesepakatan Hasil antara Kuesioner Pra Skrining Perkembangan, Parent's Evaluation of Development Status, dan Tes Denver-II untuk Skrining Perkembangan Anak Balita

Azrimaidaliza, A., Annisa, A., Khairany, Y., Prativa, N., Adrianus, R., \& Salmah, M. P. (2019). A Optimalisasi Tumbuh Kembang Balita Melalui Promosi Gizi Seimbang Di Kecamatan Koto Tangah Padang. LogistaJurnal Ilmiah Pengabdian kepada Masyarakat, 3(2), 17-26.

Depkes RI. (2010). Pedoman Pelaksanaan Stimulasi, Deteksi dan Intervensi Dini Tumbuh Kembang (SDIDTK) Anak, DepKes RI, Jakarta

Ellyda, dkk. (2018). Pelatihan Deteksi Tumbuh Kembang Anak Pada Kader Posyandu Ponowaren, Gamping, Sleman. Jurnal Pengabdian dan Pemberdayaan Masyarakat. Vol. 2 No. 2

Eun, J. J., Lee, H. J., \& Kim, J. K. (2014). Developmental profiles of preschool children with delayed language development. Korean journal of pediatrics, 57(8), 363.

Hati, F. S., \& Lestari, P. (2016). Pengaruh pemberian stimulasi pada perkembangan anak usia 12-36 bulan di Kecamatan Sedayu, Bantul. Jurnal Ners dan kebidanan indonesia, 4(1), 44-48.

Naziyah, N., Choirunnisa, R., \& Khoirunnisa, D. (2020). Penyuluhan Gizi Sehat dan Pengukuran Antropometri pada Bayi dan Balita di Posyandu Caraka Nanda III Kelurahan Pondok betung Tangerang Selatan. Jurnal Kreativitas Pengabdian Kepada Masyarakat (PKM), 3(1), 20-26.

Putri, H. A., \& Dwihestie, L. K. (2020). Optimalisasi Peran Kader Posyandu dalam Upaya Deteksi Dini Tumbuh Kembang Balita di Wilayah Beji Sidoarum Godean Sleman. Jurnal Abdimas Mahakam, 4(1), 66-72.

Yuliati, Y., \& Harjana, T. (2018). Pemberdayaan Kader Posyandu Balita Melalui Model Three Level Marketing Deteksi Dini Kelainan Tumbuh Kembang Anak. Jurnal Pengabdian Masyarakat MIPA dan Pendidikan MIPA, 2(1), 43-47. 